\title{
Uterus Transplant: Does It Have Legs?
}

\author{
C. V. Hegde ${ }^{1}$
}

Received: 12 July 2017/Accepted: 12 July 2017/Published online: 21 July 2017

(C) Federation of Obstetric \& Gynecological Societies of India 2017

\begin{abstract}
About the Author

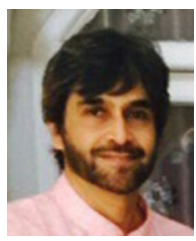

Dr C. V. Hegde is Editor in chief of 'The Journal of Obstetrics and Gynecology of India.' He is also Professor and Head of Department at the T N Medical College and BYL Nair Hospital, Mumbai. He is also Visiting Consultant at the Sir HN Reliance Foundation Hospital, Mumbai. He has had a rich teaching experience of more than three decades and has taught and trained a large number of undergraduate and postgraduate students in that duration of time. He has been a postgraduate and undergraduate examiner in Obstetrics and Gynecology at the Bombay University and the Maharashtra University of Health Sciences. He runs the PICSEP program of the Journal and FOGSI under whose aegis ten programs in research methodology are conducted all over the country every year. This program aims at improving the quality of original research papers being submitted to the journal. He has several research papers published in this journal and several other journals of standing. He is the winner of the prestigious FOGSI Corion award in the senior category. He has more than 50 videos on the YouTube on all aspects of vaginal and endoscopic surgery, solely for the purpose of furthering medical education. His other interests include nonfiction reading and reading blogs on Indian history and contemporary politics.
\end{abstract}

There are essential life-saving transplants like kidney, liver, heart and bone marrow among others. A uterus transplant does not even come near and is clearly non essential. Yet eleven documented uterus transplants have been performed in three countries in human beings to date. One of these has been from a deceased donor. The most obvious reason to perform this procedure with all its comorbidities is to treat an irreversible uterine factor in infertility including Mayer Rokitansky Kuster Hauser

Dr C. V. Hegde is Editor in chief of 'The Journal of Obstetrics and Gynecology of India.' He is also Professor and Head of Department at the T N Medical College and BYL Nair Hospital, Mumbai.

\section{V. Hegde \\ cvvh29@yahoo.co.in}

1 Mumbai, India
(MRKH) syndrome, Asherman's syndrome and an already hysterectomised patient. Uterine agenesis and hypoplasia are other causes. The treatment for a uterine factor has been adoption and surrogacy as of now. The only rationale for performing a uterus transplant seemingly is to give the woman an emotional catharsis of carrying a pregnancy till birth and affording her that 'magical' experience of motherhood.

Uterine transplants have been carried out in mice [1], rats [2], rabbits [3], sheep [4] and primates [5]. In a systematic review chronicling the uterus transplants in human beings to date [6], it was noted that the first uterus transplant done in Saudi Arabia [7] in 2002 resulted in a graft loss and hysterectomy was done after 3 months. In this case, the donor was a 46-year-old patient who underwent an abdominal hysterectomy for large bilateral multicystic ovarian masses. The recipient was a 26 -year-old patient 
who had undergone an obstetric hysterectomy for severe hemorrhage following a cesarean section. In this case, patches from the great saphenous vein of the recipient attached to the short ends of the uterine vessels of the graft were anastomosed to the external iliac vessels of the recipient. The recipient here was treated preoperatively and perioperatively with corticosteroids and postoperatively with cyclosporine, azathioprine and prednisolone as immunosuppression therapy. The second uterus transplant done in Turkey in 2011 resulted in two pregnancies, but the end result was abortion in both cases. The first was a biochemical pregnancy, while the second time an abortion occurred prior to the eighth week. [8]. In this case, the uterus transplant was done from a brain dead female 22 years of age from whom other organs were also harvested. The recipient was a 21-year-old woman with complete müllerian agenesis (MRKH syndrome) who had been previously operated on for a vaginal reconstruction using a jejunal segment. The internal iliac artery and vein of the donor were anastomosed in an end-to-side fashion to the external iliac artery and vein of the recipient. Anastomoses were performed between the 6-cm-length proximal donor vagina and the recipient's $12-\mathrm{cm}$-length neovaginal vault. After 20 days, the recipient had her first menstruation. After two irregular menstrual cycles, she was given cyclic hormonal therapy providing monthly withdrawal bleeding [9]. The methodology has been described in full detail in the paper published by Ozkan et al. [10].

A local transplantation committee was initially formed and in their own words- the committee composed of reconstructive surgeons, transplant surgeons, gynecologists, transplant psychiatrists, bioethicists, transplant infectious disease specialists, nephrologists, immunologists, and anesthesiologists. The selection criteria for candidates were good ovarian reserve, which was evaluated by measuring a patient's levels of follicle-stimulating hormone $(\mathrm{FSH})$, estradiol $\left(\mathrm{E}_{2}\right)$, and antimüllerian hormone $(\mathrm{AMH})$, as well as the patient's antral follicle count, karyotype (normal female 46, XX), liver and kidney function (normal), general health (satisfactory), body mass index (lean, BMI $\leq 25 \mathrm{~kg} / \mathrm{m}^{2}$ ), and psychological health (stable). All evaluated patients had blood group and human leukocyte antigen (HLA) tests.' Prior to the transplant, the patient and her relatives were counseled about all the possibilities of various complications and risks to life and the threat posed by postoperative immunosuppressive therapy. An informed consent was taken. The surgery itself lasted eight hours. The medication involved in this case was-' induction with thymoglobulin $(2.0 \mathrm{mg} / \mathrm{dL}$ daily; days $0-10)$. Corticosteroids were given during surgery $(1 \mathrm{~g}$ IV) and tapered during the first postoperative week. As maintenance therapy, she was given tacrolimus $(0.2 \mathrm{mg} /$ $\mathrm{kg}$ ) from day 7 onward (aiming for trough levels of
15-20 ng/mL), mycophenolate mofetil (MMF; $2 \mathrm{~g} / \mathrm{d}$ ) and corticosteroids $(20 \mathrm{mg} / \mathrm{d})$.'

The World Health Organization has guiding principles according to which organ donations from deceased donors should be developed to their maximum potential before transplant [11]. The advantage of deceased donor uteri is the reduced dissection time, obtainment of large caliber vessels like the ovarian vessels and the common iliac vessels (in the Turkish case) for anastomosis. The disadvantage is that the ischemic time is prolonged (the time required for the blood supply to start) as a result of which graft rejection is likely. This is seen in renal transplant. A challenge therefore is to reduce the cold ischemic time [12]. The ischemic time is not yet defined for the human uterus [13].

Nine patients underwent uterine transplants from live donors at Gothenburg, Sweden. Among these the first successful childbirth was in September 2014 in a 35-yearold patient with uterine agenesis who had received the uterus from a 61-year-old postmenopausal patient of 7 years [14]. Two more patients from the same group gave birth in November 2014. A clinical series involving nine transplants from live donors was performed in Sweden in 2012-2013 [15].

Of these one underwent hysterectomy in a short period of time due to uterine artery thrombosis and another due to severe intractable uterine infection. The others had menses within 4 to 8 weeks postsurgery. Live donor uteri should be obtained from women free from subfertility, systemic illnesses, myomas/adenomyosis, intrauterine adhesions, cervical and endometrial hyperplasia and human papilloma virus infection. Donor uteri should not be of inferior quality. The same criteria hold for deceased donor uteri.

The surgical retrieval of the live donor uterus is difficult and time consuming - a mean of $12 \mathrm{~h}$ [15]. The surgery involves an extensive dissection with the removal of the ovaries to ensure the availability of large ovarian veins for anastomosis. Isolation of uterine vessels in particular the uterine veins is difficult to obtain. The uterine vessels may be cut with a small patch from the iliac vessels. The large uterine vessels connected to the ovarian vessels may also be used for anastomosis. An adequate vaginal length should be obtained. Surgical complications in the donor are not known [15].

Immunotherapy used in such cases to prevent graft rejection can also result in severe side effects. A fine balancing act is necessary to achieve the ends targeted. The Swedish protocol involved-'induction with corticosteroids (IV, $500 \mathrm{mg}$ ) perioperatively and either thymoglobulin (IV, $2.5 \mathrm{mg} / \mathrm{kg}$ body weight) or antithymocyte globulin (IV, $5 \mathrm{mg} / \mathrm{kg}$ body weight) twice on the day of surgery' [15]. Maintenance therapy was with tacrolimus, aiming at trough levels of $10-15 \mathrm{ng} / \mathrm{mL}$ during the first 
month and $5-10 \mathrm{ng} / \mathrm{mL}$ from the second month onward. Oral MMF was given $(1 \mathrm{~g})$ preoperatively and from postoperative day 1, administered twice daily, and the aim was to keep the MMF area under the curve trough levels at $40-60 \mathrm{mg} / \mathrm{h} / \mathrm{L}$. Six months posttransplantation, the potentially teratogenic MMF was discontinued. In some cases, MMF had to be replaced with azathioprine [16]

Donor grafts are susceptible to rejection posttransplant, and monitoring is essential. Acute episodes of rejection are clinically manifest; however, methods to maintain a surveillance of graft function, e.g., markers like serum creatinine in renal transplant, are not available in a uterine transplant. Therefore, minimally invasive methods like a cervical biopsy at regular intervals may be of great use to detect subclinical uterus rejection or else to convey a normal environment of the transplanted uterus. An endometrial biopsy interferes with the cavity of the uterus and is ordinarily not resorted to. Other methods of monitoring the functional status of the uterus include ultrasound evaluation of the endometrium, doppler studies of uterine vascularity, visual inspection of the cervix and cervical cultures. In the Swedish study, cases of mild early rejection were countered by short courses of increased immunosuppression.

Pregnancy has been achieved only in live donor uteri by assisted reproduction. The question arises as to whether immunosuppression should be continued in the event of pregnancy in a transplanted uterus. Especially, since commonly used drugs cross the placenta and have the potential to affect the fetus in the developmental stage [17]. Data from transplant recipients of organs other than the uterus have shown that immunosuppression during pregnancy is associated with increasing trends of complications like hypertension in pregnancy, ectopic pregnancy, preterm deliveries, stillbirths and neonatal deaths [18-20].

The immunosuppressive effects on the fetus causing severe anomalies can be reduced by omitting certain drugs prior to attempting a pregnancy as per the United States Food and Drug Administration recommendations. If followed, the anomaly incidence would be similar to that in a normal pregnancy [21]. In pregnancy due to hemodynamic changes, drug levels need to be monitored and adjusted accordingly. Adequate 'trough' levels need to be maintained. In general, immunosuppressive drugs need to be increased in pregnancy and tapered off in the postpartum period [22, 23].

Immunosuppression continued till delivery is accomplished by Cesarean section (the patient does not feel fetal movements or experience contractions because the uterus is not innervated) following which the transplanted uterus is removed. In the Swedish study, the uterus was conserved in some cases in order to attempt a second pregnancy and immunotherapy was continued.
How is the saga of uterine transplant likely to play out? There are several institutions at present that recommend the procedure since it provides a chance for an affected patient to experience the ultimate supreme feeling of childbirth. Yet there are sceptics who are worried about 'copycat' procedures being indiscriminately performed by ambitious persons who bypass guidelines or are conveniently expedient with several essentials like following ethics procedures strictly, conducting repeated counseling of both donors and recipients and their families, having an experienced transplant team in position, having gynecologists who are experts in extensive pelvic dissection, having a team of immunotherapists and an assisted reproduction facility in case the graft is not rejected.

In future one could envisage shorter donor retrieval times, better surgical techniques and less morbid immunotherapy as coming with the turf if transplants continue to happen. Does this have legs? Time will be a witness as to the success of this procedure.

\section{References}

1. Avison DL, DeFaria W, Tryphonopoulos P, et al. Heterotopic uterus transplantation in a swine model. Transplantation. 2009;88(4):465-9. doi:10.1097/TP.0b013e3181b07666.

2. Lee S, Mao L, Wang $\mathrm{Y}$, et al. Transplantation of reproductive organs. Microsurgery. 1995;16(4):191-8. doi:10.1002/micr. 1920160406.

3. Confino E, Vermesh M, Thomas W, et al. Non-vascular transplantation of the rabbit uterus. Int $\mathrm{J}$ Gynaecol Obstet. 1986;24(4):321-5. doi:10.1016/0020-7292(86)90091-3.

4. Zhordania IF, Gotsiridze OA. Vital activity of the excised uterus and its appendages after their autotransplantation into omentum. Experimental research. Acta Chir Plast. 1964;6:23-32.

5. Scott JR, Pitkin RM, Yannone ME. Transplantation of the primate uterus. Surg Gynecol Obstet. 1971;133(3):414-8.

6. Ejzenberg D, Mendes LRBC, Haddad LBP, et al. Uterine transplantation: a systematic review. Clinics (Sao Paulo). 2016;71(11):679-83. doi:10.6061/clinics/2016(11)10.

7. Fageeh W, Raffa H, Jabbad H, et al. Transplantation of the human uterus. Int J Gynaecol Obstet. 2002;76(3):245-51. doi: 10.1016/S0020-7292(01)00597-5.

8. Erman Akar M, Ozkan O, Aydinuraz B, et al. Clinical pregnancy after uterus transplantation. Fertil Steril. 2013;100(5):1358-63. doi:10.1016/j.fertnstert.2013.06.027.

9. Ozkan O, Akar ME, Erdogan O, et al. Uterus transplantation from a deceased donor. Fertil Steril. 2013;100(6):e41.

10. Ozkan O, Akar ME, Ozkan O, et al. Preliminary results of the first human uterus transplantation from a multiorgan donor. Fertil Steril. 2013;99(2):470-6. doi:10.1016/j.fertnstert.2012.09.035.

11. Sixty-Third World Health Assembly. World Health Organization WHO guiding principles on human cell, tissue and organ transplantation. Cell Tissue Bank. 2010;11(4):413-9.

12. Schwarz A, Mengel M, Gwinner W, et al. Risk factors for chronic allograft nephropathy after renal transplantation: a protocol biopsy study. Kidney Int. 2005;67(1):341-8.

13. Stahl JE, Kreke JE, Malek FA, et al. Consequences of coldischemia time on primary nonfunction and patient and graft 
survival in liver transplantation: a meta-analysis. PLoS ONE. 2008;3(6):e2468.

14. Brännström $M$, Johannesson $L$, Bokström $H$, et al. Livebirth after uterus transplantation. Lancet. 2015;385(9968):607-16. doi: 10.1016/S0140-6736(14)61728-1.

15. Brannstrom M, Johannesson L, Dahm-Kahler P, et al. First clinical uterus transplantation trial: a six-month report. Fertil Steril. 2014;101(5):1228-36.

16. Johannesson L, Järvholm S. Uterus transplantation: current progress and future prospects. Int J Womens Health. 2016;8:43-51. doi:10.2147/IJWH.S75635.

17. Ostensen M. Disease specific problems related to drug therapy in pregnancy. Lupus. 2004;13(9):746-50.

18. Armenti VT, Radomski JS, Moritz MJ, et al. Report from the National Transplantation Pregnancy Registry (NTPR): outcomes of pregnancy after transplantation. Clin Transpl. 2004;2004:103-14.
19. Briggs JD, Jager K. The first year of the new ERA-EDTA registry. Nephrol Dial Transpl. 2001;16(6):1130-1.

20. Sibanda N, Briggs JD, Davison JM, et al. Pregnancy after organ transplantation: a report from the UK Transplant pregnancy registry. Transplantation. 2007;83(10):1301-7.

21. McKay DB, Josephson MA. Pregnancy in recipients of solid organs-effects on mother and child. $N$ Engl $J$ Med. 2006;354(12):1281-93.

22. Tendron A, Gouyon JB, Decramer S. In utero exposure to immunosuppressive drugs: experimental and clinical studies. Pediatr Nephrol. 2002;17(2):121-30.

23. Akturk S, Celebi ZK, Erdogmus S, et al. Pregnancy after kidney transplantation: outcomes, tacrolimus doses, and trough levels. Transplant Proc. 2015;47(5):1442-4. 